\title{
Review Article \\ Copeptin Testing in Acute Myocardial Infarction: Ready for Routine Use?
}

\author{
Sebastian Johannes Reinstadler, Gert Klug, Hans-Josef Feistritzer, \\ Bernhard Metzler, and Johannes Mair \\ Department of Internal Medicine III, Cardiology and Angiology, Medical University of Innsbruck, Anichstraße 35, \\ 6020 Innsbruck, Austria \\ Correspondence should be addressed to Johannes Mair; johannes.mair@i-med.ac.at
}

Received 6 October 2014; Accepted 12 January 2015

Academic Editor: Serge Masson

Copyright (C) 2015 Sebastian Johannes Reinstadler et al. This is an open access article distributed under the Creative Commons Attribution License, which permits unrestricted use, distribution, and reproduction in any medium, provided the original work is properly cited.

\begin{abstract}
Suspected acute myocardial infarction is one of the leading causes of admission to emergency departments. In the last decade, biomarkers revolutionized the management of patients with suspected acute coronary syndromes. Besides their pivotal assistance in timely diagnosis, biomarkers provide additional information for risk stratification. Cardiac troponins I and $\mathrm{T}$ are the most sensitive and specific markers of acute myocardial injury. Nonetheless, in order to overcome the remaining limitations of these markers, novel candidate biomarkers sensitive to early stage of disease are being extensively investigated. Among them, copeptin, a stable peptide derived from the precursor of vasopressin, emerged as a promising biomarker for the evaluation of suspected acute myocardial infarction. In this review, we summarize the currently available evidence for the usefulness of copeptin in the diagnosis and risk stratification of patients with suspected acute myocardial infarction in comparison with routine biomarkers.
\end{abstract}

\section{Introduction}

The discovery of the biomarker cardiac troponin (cTn) as well as its introduction as a test into clinical routine has been one of the most important advances in the evaluation of patients with suspected acute myocardial infarction (AMI) over the last decades. Today, cTn plays a key role in the management of patients with acute coronary syndromes (ACS) [1]. A further clinically relevant increase in the sensitivity of cTn at an early diagnostic stage was achieved with the introduction of high-sensitivity (hs) cTn assays [2-4]. Despite these advances, there remains a troponin-blind period very early after symptom onset. Therefore, in patients with suspected AMI, a ruleout process with cTn measurement at presentation and 3 hours thereafter is still required when hs-cTn assays are used $[5,6]$. Efforts to discover new biomarkers enabling a reliable earlier rule-out of AMI and thus a reduction of unnecessary hospital admissions are continuing. Besides its pivotal role as a diagnostic tool, cTn provides also information for risk assessment in the setting of ACS and many other cardiac and noncardiac diseases [5, 7-14]. Other promising biomarkers for risk stratification are natriuretic peptides (NPs) $[7,15,16]$ and high-sensitivity C-reactive protein (hs-CRP) [17-19]. In the context of AMI, however, the incremental value of these biomarkers beyond conventional risk factors seems to be only moderate, and true large-scale comparative studies are still missing. Therefore, the role of novel biomarkers other than that of the routinely used cTn, NPs, and hs-CRP that might enable a better risk stratification of patients with chest pain is being increasingly investigated [20-25]. One of the most frequently proposed and extensively investigated biomarkers for facilitating the diagnosis of AMI is copeptin [6]. In addition, copeptin was also evaluated for risk stratification in this patient cohort. In this review, we will summarize the current clinical evidence for its routine use in patients with suspected AMI.

\section{Pathophysiology of Copeptin}

Located on chromosome 20, the gene named arginine vasopressin (AVP) encodes a 164-amino-acid peptide called pre- 
pro-AVP, which is produced by neurons of the hypothalamoneurohypophysial system [26]. The mature pre-pro-AVP is the precursor molecule for AVP, which also includes a signal peptide, neurophysin II, and copeptin [27]. Copeptin (or C-terminal provasopressin) is a glycosylated 39-amino-acid peptide. As physiological function copeptin is believed to be involved in the proper folding of pre-pro-AVP $[28,29]$. After transportation from the hypothalamus to the pituitary gland and cleavage of the pre-pro-AVP, copeptin is released into the circulation in stoichiometric amounts along with AVP. Both neuropeptides are primarily cosecreted in response to hemodynamic or osmotic alterations. The measurement of circulating AVP is challenging since AVP is an unstable molecule and because it is mainly bound to platelets [3032]. Unlike AVP, copeptin is relatively stable in the circulation and methodologically easier to determine [31]. Therefore, copeptin is used as a surrogate marker for AVP release and an assay suitable for routine use has been developed [31].

In recent years, copeptin has been considered as a promising biomarker in numerous acute illnesses [33]. For instance, an association between elevated levels of copeptin and an unfavourable outcome were reported in patients with lower respiratory tract infections [34], sepsis [35], stroke [36], and acute pancreatitis [37]. These studies have consistently demonstrated a positive association between copeptin and disease severity. The role of copeptin has also gained particular attention in patients with AMI. Circulating copeptin levels are significantly higher during the acute phase in patients with AMI compared with healthy control subjects [38]. The copeptin elevation is again greater in patients with ST-segment elevation myocardial infarction (STEMI) than in patients with non-ST-segment elevation acute coronary syndrome (NSTE-ACS). The main trigger for copeptin release after AMI is thought to be acute endogenous stress $[39,40]$. On the other hand, copeptin secretion is also associated with changes in fluid status [41]. Thus, it can be assumed that hemodynamic changes occurring in the acute phase during AMI might also trigger copeptin release [40]. In an animal study by Hupf et al., it was shown that vasopressin is also expressed in cardiac tissue [42]. Some authors speculate that myocardial necrosis could therefore directly lead to copeptin release from the heart [40, 43]. The release pattern of copeptin was recently described in detail $[40,43]$. It is important to note that, in contrast to the MB isoenzyme of creatine kinase (CK-MB) and cTn, copeptin concentrations rise immediately after symptom onset and decrease rapidly thereafter (Figure 1). A direct association between the amount of released copeptin, on the one hand, and acute as well as chronic infarct size determined by cardiac magnetic resonance imaging, on the other, was demonstrated in STEMI patients $[44,45]$. It is important to note, however, that, in contrast to $\mathrm{cTn}$, increased copeptin levels are not specific for myocardial damage (see Table 1). For instance, Stallone et al. showed that increased levels of copeptin were measureable in about one-fifth of patients presenting to the emergency department with noncardiac chest pain [46].

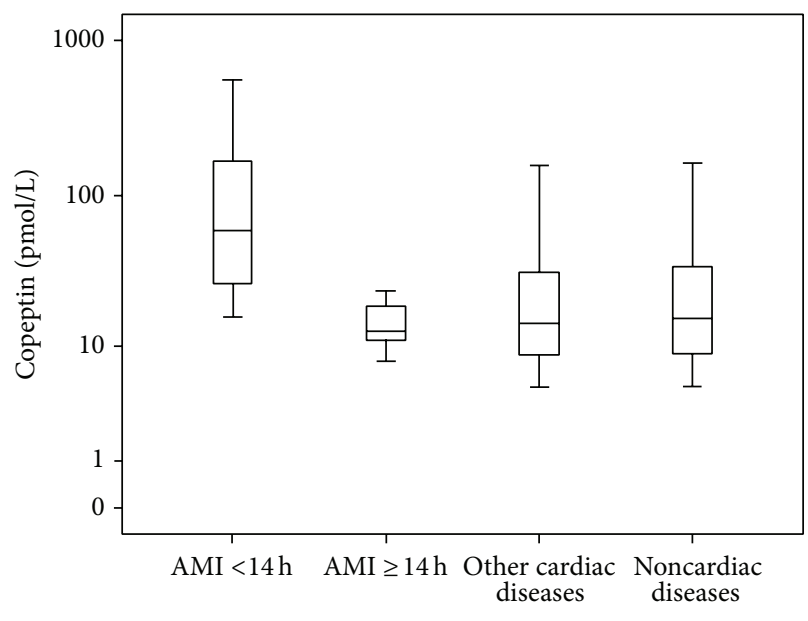

FIgURE 1: Distribution pattern of copeptin in patients with chest pain admitted to the emergency department $(n=171)$ according to discharge diagnosis. Our own unpublished data are shown as box plots. AMI patients were divided by delay from symptom onset. Copeptin concentrations in AMI patients presenting within $14 \mathrm{~h}$ from symptom onset were significantly $(P=0.013)$ higher than in the remaining patients, whereas AMI patients presenting thereafter did not differ significantly. Abbreviations-AMI: acute myocardial infarction.

\section{Copeptin for the Diagnosis of Acute Myocardial Infarction}

3.1. "Rule-In" of Acute Myocardial Infarction. As mentioned above, copeptin shows only low specificity for myocardial damage. Accordingly, the positive predictive value (PPV) for AMI of copeptin alone is thought to be unacceptably low. Indeed, the first studies investigating the diagnostic value of copeptin for AMI showed a very low PPV for AMI $[47,48]$. For instance, Reichlin et al. calculated the PPV of copeptin for AMI diagnosis for different cut-off concentrations ( $9 \mathrm{pmol} / \mathrm{L}$, $14 \mathrm{pmol} / \mathrm{L}, 20 \mathrm{pmol} / \mathrm{L}$, and $24 \mathrm{pmol} / \mathrm{L})$. In their study, the PPV of copeptin ranged between $34.9 \%$ and $57.9 \%$. Two recently published meta-analyses confirmed that copeptin alone provides only insignificant diagnostic value in the setting of suspected AMI $[49,50]$. Therefore, copeptin alone should not be considered as a single diagnostic marker in patients with suspected ACS.

\section{2. "Rule-Out" of Acute Myocardial Infarction of Copeptin in} Combination with Standard cTn and hs-cTn. On the basis of its unique release pattern, it was speculated that the combination of copeptin with cTn might facilitate the early "ruleout" of AMI. In fact, in the landmark trial published by Reichlin et al. in 2009, the authors concluded that the combination of copeptin and cTn enables a rapid and safe rule-out of AMI at presentation [47]. In their study, they investigated 487 unselected emergency department (ED) patients with symptoms suggestive of AMI. The combination of copeptin and cTn reached a sensitivity of $98.8 \%$ and a negative predictive value of $99.7 \%$ for ruling-out of AMI already at presentation. The combination performed significantly better 
TABLE 1: Overview of clinical conditions other than AMI associated with increased copeptin concentrations.

\begin{tabular}{|c|c|c|}
\hline Condition & Potential implications of elevated copeptin concentrations & References \\
\hline $\begin{array}{l}\text { Stable coronary artery } \\
\text { disease }\end{array}$ & Predictor for major adverse cardiovascular events & {$[51]$} \\
\hline Heart failure & Associated with mortality risk, risk of hospitalization, and disease severity & {$[52-56]$} \\
\hline Type 2 diabetes & $\begin{array}{l}\text { Potential marker for peripheral arterial disease and diabetic chronic kidney disease. } \\
\text { Potential marker for cardiovascular and all-cause mortality }\end{array}$ & {$[57-59]$} \\
\hline Pneumonia & Marker for adverse outcome & {$[60,61]$} \\
\hline $\begin{array}{l}\text { Acute exacerbation of } \\
\text { chronic obstructive } \\
\text { pulmonary disease }\end{array}$ & Potential prognostic marker for short-term and long-term outcome & {$[62]$} \\
\hline Sepsis/shock & Promising independent prognostic markers for mortality & {$[33,35,63]$} \\
\hline Survivors of cardiac arrest & Potentially useful for risk stratification at the time of hospital admission & {$[64]$} \\
\hline $\begin{array}{l}\text { Pulmonary arterial } \\
\text { hypertension }\end{array}$ & Potentially useful in the prediction of poor outcome & {$[65]$} \\
\hline $\begin{array}{l}\text { Stroke/transient ischaemic } \\
\text { attack }\end{array}$ & Risk stratification for patients with transient ischaemic attack and stroke & {$[66-68]$} \\
\hline Traumatic brain injury & $\begin{array}{l}\text { Probable marker of progressive haemorrhagic injury, acute traumatic coagulopathy, } \\
\text { and mortality }\end{array}$ & {$[69-71]$} \\
\hline Intracerebral haemorrhage & Useful to predict adverse clinical outcomes & {$[72,73]$} \\
\hline Carotid endarterectomy & Probable predictor of perioperative stroke & {$[74]$} \\
\hline CABG surgery & $\begin{array}{l}\text { Postoperative copeptin concentrations might predict delirium and cognitive } \\
\text { dysfunction }\end{array}$ & {$[75]$} \\
\hline Chronic kidney disease & Potential marker for the development/progression of atherosclerosis & {$[76]$} \\
\hline $\begin{array}{l}\text { Autosomal dominant } \\
\text { polycystic kidney disease }\end{array}$ & Potential role in disease progression & {$[77,78]$} \\
\hline $\begin{array}{l}\text { Carbon monoxide } \\
\text { poisoning }\end{array}$ & $\begin{array}{l}\text { Associated with intoxication severity and potentially useful to predict delayed } \\
\text { neurological sequelae }\end{array}$ & {$[79]$} \\
\hline Polycystic ovary syndrome & Relationship with cardiometabolic parameters (e.g., carotid intima media thickness) & {$[80]$} \\
\hline Endometriosis & Direct association with disease severity & {$[81]$} \\
\hline Preeclampsia & Associated with increased risk for preeclampsia already before clinical diagnosis & {$[82,83]$} \\
\hline Acute pancreatitis & Marker for disease severity and local complications & {$[37,84]$} \\
\hline Liver cirrhosis & $\begin{array}{l}\text { Associated with the severity of disease and with the risk of death or liver } \\
\text { transplantation }\end{array}$ & {$[85]$} \\
\hline Sickle cell anaemia & Differentiation between mild or severe sickle cell anaemia & {$[86]$} \\
\hline
\end{tabular}

Aortocoronary bypass grafting (CABG).

compared to cTn alone. In addition, with the use of the dual marker strategy, the diagnostic accuracy was high for the diagnosis of AMI at presentation (area under the curve: 0.97). Nevertheless, some important limitations have to be mentioned. Although the cohort was comparable with other similar trials, it has all the limitations of a single-centre study. More importantly, a non-hs cTn assay was used, which was appropriate at that time but would not be today. Following this study, there have been a great number of reports confirming [48, 87-94] or rejecting [23, 95-99] this hypothesis. There are various reasons for these conflicting results. As mentioned before, one crucial point is the use of non-hs-cTn assay. hs-cTnT assays have been shown to provide a better early diagnostic sensitivity for AMI in the ED compared with the previous cTn assay generations $[2,100,101]$. Not surprisingly, almost all studies comparing copeptin with cTn assessed by a conventional assay display a substantial benefit of the dual marker approach. In contrast, when an hs-cTn is used, the benefit seems to be only moderate or absent [49] (Figure 2). The additive value seems to be especially low when the limit of detection (LoD) of hs-cTn is used as a decision limit for ruling out of AMI. This is of little surprise, since trials using LoD as "rule-out" criterion found a negative predictive value of up to $100 \%[102,103]$. On the other hand, a more sensitive assay for the determination of copeptin has been developed and is available for routine use as well [91]. This assay enables a more precise measurement of copeptin, which could also explain in part the differences in the "rule-out" studies. Moreover, initially performed studies used a copeptin cut-off value of $14 \mathrm{pmol} / \mathrm{L}$, whereas recent data suggest that $10 \mathrm{pmol} / \mathrm{L}$ might be a more appropriate decision limit [49]. Another vital issue is the time point of copeptin sampling. As mentioned earlier, copeptin concentration increases to maximum immediately after symptom onset and decreases within hours thereafter. Hence, the proposed dual marker strategy is only reasonable in early presenters and when blood 


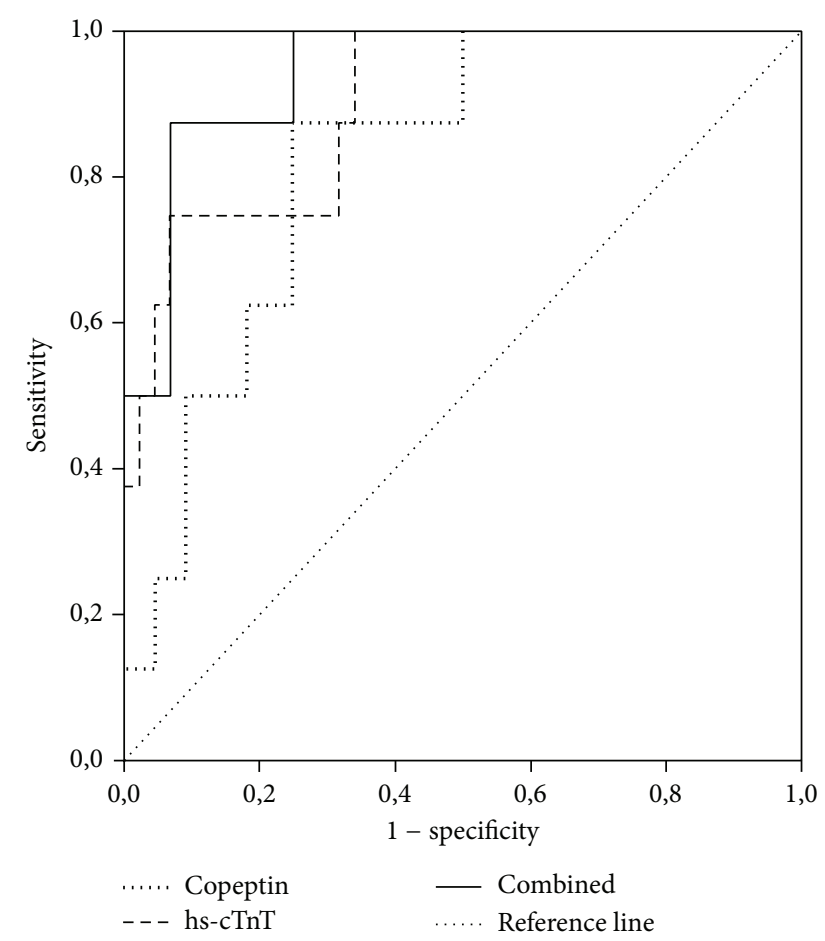

FIGURE 2: ROC analysis to compare the diagnostic power of copeptin, hs-cTnT, and the combination of both for the diagnosis of AMI in patients presenting with chest pain early after symptom onset (within 14 hours) on admission. Own unpublished data. The AUC of hs-cTnT (0.90, 95\% confidence interval 0.79-0.97) did not differ significantly from the AUC of copeptin combined with hs$c \operatorname{TnT}(0.94,95 \%$ confidence interval $0.84-0.99 ; P>0.05)$. Abbreviations-ROC: receiver operating characteristic; hs-cTnT: highsensitivity cardiac troponin T; AMI: acute myocardial infarction; AUC: area under the curve.

samples are drawn as early as possible. This fact might explain some negative studies when copeptin was measured with a notably delay after patient presentation [98].

\section{3. "Rule-Out" of Acute Myocardial Infarction-Meta-Anal-} $y$ sis and Interventional Trials. Meta-analyses performed so far have concluded that copeptin added to cTn results in significantly increased sensitivity for the diagnosis of AMI compared with cTn alone [49]. Of note, they also conclude that copeptin is most useful when combined with conventional cTn, and the added value remains uncertain when hscTn is used. The results of this meta-analysis, however, have to be interpreted with caution. Considerable heterogeneity among studies limits the interpretation of data. Furthermore, the literature search for this meta-anylisis was carried out in 2013. Important negative studies published in $2014[95,96]$ are therefore not included in analysis.

Probably the most important drawback of all above-mentioned studies is their observational design. In these studies, the measured copeptin value did not influence patient management. Management studies, however, showing that this novel approach is effective and safe are indispensable before copeptin can be recommended for routine use. Recently, the first and so far the only randomized, multicentre clinical process trial was published [104]. In this very important study by Möckel et al., 902 low-risk patients with suspected ACS were randomly assigned to either standard care (serial cTn testing as recommended) or an experimental arm. In the experimental arm, copeptin was measured in addition to cTn and if both biomarkers tested negative, the patient was eligible for discharge without the need for serial cTn testing. It needs to be mentioned that, in the latter case, the treating physician could still decide not to discharge the patient immediately. The primary safety study end-point was defined as combination of all-cause death, survived sudden cardiac death, AMI, rehospitalization for ACS, acute unplanned percutaneous coronary intervention, coronary artery bypass grafting, and documented life-threatening arrhythmia 30 days after enrollment. The authors found a similar event rate (standard arm: 5.17\%, experimental arm: 5.19\%) in both study arms, suggesting that the combined cTn/copeptin strategy is as safe as the standard procedure. The advantage of the new approach was also clearly demonstrated. In the experimental arm, hospital stay was significantly shorter compared with standard arm ( 4 versus 7 hours, resp., $P<0.001$ ). The main conclusion was therefore that a dual marker strategy with copeptin and cTn could safely decrease length of hospital stay. Although the study was well designed, there are some relevant limitations that have to be considered. cTn was measured by different conventional (three sites) as well as high-sensitive assays (four sites) across the study sites. Furthermore, the thresholds for a "negative" cTn result were defined by the 99th percentile upper reference limit. By using the LoD as cut-off, the negative predictive value of cTn can be further increased as demonstrated by recent studies [103]. In the era of hs-cTn assays, a crucial study would be the direct of comparison of hs-cTn versus copeptin plus hs-cTn with the LoD as a ruleout cut-off for hs-cTn. Whether copeptin still provides an incremental value in this case remains to be investigated.

3.4. "Rule-Out" of Acute Myocardial Infarction in Point-ofCare Testing. In times of overcrowding of the emergency departments, point-of-care testing (POCT) becomes increasingly appealing. Recent evidence suggests that POCT might allow a fast and accurate diagnosis of AMI [105]. Nowadays, cTn is the most efficient diagnostic marker also in POCT [105]. Because of the lower sensitivity of POCT, cTn assays [106] compared to assays used in the central laboratory and the early period of "troponin blindness" novel biomarkers might improve the early diagnostic sensitivity in POCT. The use of the CK-MB and myoglobin was recently tested but failed to improve diagnostic performance [105]. The different release kinetics of copeptin compared with cardiac troponin after AMI makes copeptin a very promising candidate for POCT [40]. Furthermore, the encouraging results for the combination of copeptin with standard troponin assays used in central laboratory analysis suggest that a significant improvement might be possible also in POCT. Till now, prospective randomised trials are missing, but a dual marker POCT strategy including copeptin and cTn is worth being prospectively evaluated in future studies. 


\section{Copeptin for Risk Stratification in Acute Coronary Syndromes}

In order to optimize timing and intensity of therapeutic interventions as part of patient management, adequate risk stratification at an early stage after ACS is necessary [5]. Early echocardiography data revealed that copeptin concentrations, assessed 3-5 days after AMI, are correlated with left ventricular dysfunction as well as remodelling 5 months after the event [107]. More recent cardiovascular magnetic resonance studies confirmed the association between copeptin, myocardial function, and adverse remodelling following STEMI treated with primary coronary intervention [44, 45]. Interestingly, the combination of day 2 copeptin and NTproBNP levels could exclude the development of adverse remodelling over 4 months after AMI. One might therefore speculate that STEMI patients with increased copeptin concentrations after revascularization might benefit from more intense therapeutic regimens [108].

Whether copeptin is of prognostic value among patients with AMI was studied for the first time by Khan et al. in the Leicester Acute Myocardial Infarction Peptide (LAMP) study [38]. In this single-centre study of 980 consecutive patients with AMI, increased values of copeptin (odds ratio: 4.14, $P<0.0005)$ measured between days 3 and 5 after AMI were associated with the primary end-point of death or heart failure at 60 days in multivariate analysis. The area under the curve (AUC) for the prediction of the primary endpoint for copeptin (0.75) was similar to that of NT-proBNP (0.76). Interestingly, the combination of both biomarkers led to a significant improvement of AUC (0.84), suggesting that a dualmarker strategy might be more useful for risk assessment in patients suffering an AMI. Because approximately $80 \%$ of the included patients in LAMP had a STEMI, a second study with only non-ST segment elevation-ACS (NSTE-ACS) patients was performed by the same study group [109]. The LAMP II study showed in 754 NSTE-ACS patients that copeptin (measured within 24 hours after admission) is an independent predictor of all-cause mortality at 6 months. In contrast to NT-proBNP, copeptin yielded a significant net reclassification improvement of $13 \%(P=0.008)$ when added to the GRACE score.

The prognostic utility of copeptin levels on admission to hospital in patients with suspected AMI was recently documented in a prospective, single-centre study by Afzali et al. [110]. In this study of 230 patients, 107 had the final diagnosis of AMI (24 STEMI and 83 NSTE-ACS). The authors showed that levels of copeptin on admission significantly predict 180-day mortality. The AUC of copeptin (0.81) was higher compared with the AUC of cTnI (0.76) and the combination of both biomarkers $(0.83)$ performed again better than either marker alone. Although copeptin measured at admission in 377 NSTE-ACS patients was related to death within one month after the index event, this association did not remain significant after adjusting for baseline characteristics or cTn levels in the COPED-PAO study [111].

To further elucidate the value of biomarkers in the postAMI risk assessment, a recently published large study by O'Malley et al. compared the prognostic performance of multiple biomarkers sampled at enrollment among 4,432 prospectively recruited subjects with NSTE-ACS [20]. The authors conclude that, although cTn-I performed best among all investigated outcomes, copeptin seems a robust prognosticator for cardiovascular death and heart failure beyond established biomarkers. Therefore, copeptin appears promising for improving risk stratification in conjunction with other biomarkers. Of note, the authors could confirm previous data from the LAMP study indicating that copeptin is less suited to predict recurrent ischaemia. This might be explained by the fact that copeptin is primarily released in response to hemodynamic stimuli, but not by progression of atherosclerosis. A meta-analysis published in 2014 showed that the predictive value of copeptin and cTn for all-cause mortality is the same [49].

A relevant limitation of the above-mentioned studies is that none of these compared copeptin with hs-cTn. One study investigating the combination of these two biomarkers was recently published [112]. Patients with preexisting coronary artery disease and symptoms indicating AMI $(n=$ 433) were analysed in a prospective multicentre fashion. Copeptin determined on admission provided prognostic information for the risk of death at 1 year after enrollment. More importantly, the combination of copeptin with hs-cTn yielded significantly enhanced prognostic accuracy. Further investigations are warranted to confirm these promising data.

A further important question is the time point of copeptin testing. Great between-study heterogeneity exists regarding the time point of copeptin sampling. Studies measuring copeptin at different time points during the (sub-) acute phase after ACS are lacking and therefore the optimal time point for assessing copeptin concentration remains unknown.

Another major drawback of the currently available evidence is that no study evaluated a copeptin (or multimarker) based therapeutic decision pathway. Prospective interventional trials are warranted to elucidate if measurement of copeptin provides additional information beyond established risk tools that impact treatment decisions which might improve patient outcome.

\section{Summary}

For the diagnostic evaluation of AMI, cTn remains the "gold standard" biomarker. There is enough evidence from observational studies indicating that a dual marker strategy combining measurments of copeptin and cTn levels using a conventional assay might facilitate the "rule-out" of AMI in early presenters. Also in POCT, such a dual strategy seems promising, but randomized clinical trials are lacking. However, when hs-cTn assays are used, the advantage of this approach seems insignificant. Data from a first randomized, controlled clinical process trial are promissing as they suggest that this new strategy allows early and safe discharge, but further prospective interventional trials are needed to confirm those results for the combination of copeptin with hscTn. Real-world data from large regrities are also necessary to accurately evaluate this strategy. Therefore, based on the currently available body of evidence, we do not believe that 
copeptin testing can yet be recommended for use in routine clinical practice if hs-cTn assay is used.

For prognostic evaluation, current data support the use of copeptin, integrated into a multimarker approach, to improve the classification of AMI patients into different risk groups early after the acute event. However, studies showing that a biomarker-guided strategy for risk stratification improves patient outcome are needed before testing for copeptin (and other biomarkers) can be recommended for implementation in clinical routine.

\section{Conflict of Interests}

The authors declare that there is no conflict of interests regarding the publication of this paper.

\section{References}

[1] K. Thygesen, J. S. Alpert, A. S. Jaffe et al., "Third universal definition of myocardial infarction," European Heart Journal, vol. 33, no. 20, pp. 2551-2567, 2012.

[2] T. Reichlin, W. Hochholzer, S. Bassetti et al., "Early diagnosis of myocardial infarction with sensitive cardiac troponin assays," New England Journal of Medicine, vol. 361, no. 9, pp. 858-867, 2009.

[3] T. Keller, T. Zeller, D. Peetz et al., "Sensitive troponin I assay in early diagnosis of acute myocardial infarction," The New England Journal of Medicine, vol. 361, no. 9, pp. 868-877, 2009.

[4] J. Mair, "High-sensitivity cardiac troponins in everyday clinical practice," World Journal of Cardiology, vol. 6, no. 4, pp. 175-182, 2014.

[5] C. W. Hamm, J.-P. Bassand, S. Agewall et al., "ESC guidelines for the management of acute coronary syndromes in patients presenting without persistent ST-segment elevation: the Task Force for the management of acute coronary syndromes (ACS) in patients presenting without persistent ST-segment elevation of the European Society of Cardiology (ESC)," European Heart Journal, vol. 32, no. 23, pp. 2999-3054, 2011.

[6] C. Mueller, "Biomarkers and acute coronary syndromes: an update," European Heart Journal, vol. 35, no. 9, pp. 552-556, 2014.

[7] S. K. James, B. Lindahl, A. Siegbahn et al., "N-terminal probrain natriuretic peptide and other risk markers for the separate prediction of mortality and subsequent myocardial infarction in patients with unstable coronary artery disease: a global utilization of strategies to open occluded arteries (GUSTO)-IV substudy," Circulation, vol. 108, no. 3, pp. 275-281, 2003.

[8] C. W. Hamm, B. U. Goldmann, C. Heeschen, G. Kreymann, J. Berger, and T. Meinertz, "Emergency room triage of patients with acute chest pain by means of rapid testing for cardiac troponin T or troponin I," The New England Journal of Medicine, vol. 337, no. 23, pp. 1648-1653, 1997.

[9] G. Klug, A. Mayr, J. Mair et al., "Role of biomarkers in assessment of early infarct size after successful p-PCI for STEMI," Clinical Research in Cardiology, vol. 100, no. 6, pp. 501-510, 2011.

[10] M. Furtner, T. Ploner, A. Hammerer-Lercher, R. Pechlaner, and J. Mair, "The high-sensitivity cardiac troponin T assay is superior to its previous assay generation for prediction of 90-day clinical outcome in ischemic stroke," Clinical Chemistry and Laboratory Medicine, vol. 50, no. 11, pp. 2027-2029, 2012.

[11] G. E. Cramer, M. A. Brouwer, H. L. Vader et al., "Highly sensitive cardiac troponin $\mathrm{T}$ and long-term mortality in a population of community-derived perimenopausal women: nested case-control study," Heart, vol. 99, no. 8, pp. 528-533, 2013.

[12] T. Kubo, H. Kitaoka, S. Yamanaka et al., "Significance of highsensitivity cardiac troponin T in hypertrophic cardiomyopathy," Journal of the American College of Cardiology, vol. 62, no. 14, pp. 1252-1259, 2013.

[13] A. M. C. Neukamm, A. D. Høiseth, T.-A. Hagve, V. Søyseth, and T. Omland, "High-sensitivity cardiac troponin T levels are increased in stable COPD," Heart, vol. 99, no. 6, pp. 382-387, 2013.

[14] A. Dispenzieri, M. A. Gertz, S. K. Kumar et al., "High sensitivity cardiac troponin $\mathrm{T}$ in patients with immunoglobulin light chain amyloidosis," Heart, vol. 100, no. 5, pp. 383-388, 2014.

[15] A. Mayr, J. Mair, M. Schocke et al., "Predictive value of NTpro BNP after acute myocardial infarction: relation with acute and chronic infarct size and myocardial function," International Journal of Cardiology, vol. 147, no. 1, pp. 118-123, 2011.

[16] K. Thygesen, J. Mair, C. Mueller et al., "Recommendations for the use of natriuretic peptides in acute cardiac care: a position statement from the Study Group on Biomarkers in Cardiology of the ESC Working Group on Acute Cardiac Care," European Heart Journal, vol. 33, no. 16, pp. 2001-2006, 2012.

[17] D. A. Morrow, N. Rifai, E. M. Antman et al., "C-reactive protein is a potent predictor of mortality independently of and in combination with troponin $\mathrm{T}$ in acute coronary syndromes: a TIMI 11A substudy," Journal of the American College of Cardiology, vol. 31, no. 7, pp. 1460-1465, 1998.

[18] K. Thygesen, J. Mair, E. Giannitsis et al., "How to use high-sensitivity cardiac troponins in acute cardiac care," European Heart Journal, vol. 33, no. 18, pp. 2252-2257, 2012.

[19] A. Mayr, G. Klug, M. Schocke et al., "Late microvascular obstruction after acute myocardial infarction: relation with cardiac and inflammatory markers," International Journal of Cardiology, vol. 157, no. 3, pp. 391-396, 2012.

[20] R. G. O'Malley, M. P. Bonaca, B. M. Scirica et al., "Prognostic performance of multiple biomarkers in patients with non-STsegment elevation acute coronary syndrome: analysis from the MERLIN-TIMI 36 trial (Metabolic Efficiency with Ranolazine for Less Ischemia in Non-ST-Elevation Acute Coronary Syndromes-Thrombolysis in Myocardial Infarction 36)," Journal of the American College of Cardiology, vol. 63, no. 16, pp. 1644-1653, 2014.

[21] R. A. P. Weir, A. M. Miller, G. E. J. Murphy et al., "Serum soluble ST2: a potential novel mediator in left ventricular and infarct remodeling after acute myocardial infarction," Journal of the American College of Cardiology, vol. 55, no. 3, pp. 243-250, 2010.

[22] G. Klug, H. J. Feistritzer, S. J. Reinstadler et al., "Association of aortic stiffness with biomarkers of myocardial wall stress after myocardial infarction," International Journal of Cardiology, vol. 173, no. 2, pp. 253-258, 2014.

[23] M. Reiter, R. Twerenbold, T. Reichlin et al., "Heart-type fatty acid-binding protein in the early diagnosis of acute myocardial infarction," Heart, vol. 99, no. 10, pp. 708-714, 2013.

[24] S. J. Reinstadler, G. Klug, H. J. Feistritzer et al., "Relation of plasma adiponectin levels and aortic stiffness after acute STsegment elevation myocardial infarction," European Heart Journal: Acute Cardiovascular Care, vol. 3, no. 1, pp. 10-17, 2014.

[25] F. Cappellini, S. Da Molin, S. Signorini et al., "Heart-type fatty acid-binding protein may exclude acute myocardial infarction on admission to emergency department for chest pain," Acute Cardiac Care, vol. 15, no. 4, pp. 83-87, 2013. 
[26] M. J. Brownstein, J. T. Russell, and H. Gainer, "Synthesis, transport and release of posterior pituitary hormones," Science, vol. 207, no. 4429, pp. 373-378, 1980.

[27] C. P. Mahoney, E. Weinberger, C. Bryant, M. Ito, and J. L. Jameson, "Effects of aging on vasopressin production in a kindred with autosomal dominant neurohypophyseal diabetes insipidus due to the Deltae47 neurophysin mutation," Journal of Clinical Endocrinology and Metabolism, vol. 87, no. 2, pp. 870-876, 2002.

[28] C. Barat, L. Simpson, and E. Breslow, "Properties of human vasopressin precursor constructs: inefficient monomer folding in the absence of copeptin as a potential contributor to diabetes insipidus," Biochemistry, vol. 43, no. 25, pp. 8191-8203, 2004.

[29] N. G. Morgenthaler, J. Struck, S. Jochberger, and M. W. Dünser, "Copeptin: clinical use of a new biomarker," Trends in Endocrinology and Metabolism, vol. 19, no. 2, pp. 43-49, 2008.

[30] G. L. Robertson, E. A. Mahr, S. Athar, and T. Sinha, "Development and clinical application of a new method for the radioimmunoassay of arginine vasopressin in human plasma," The Journal of Clinical Investigation, vol. 52, no. 9, pp. 2340-2352, 1973.

[31] N. G. Morgenthaler, J. Struck, C. Alonso, and A. Bergmann, "Assay for the measurement of copeptin, a stable peptide derived from the precursor of vasopressin," Clinical Chemistry, vol. 52, no. 1, pp. 112-119, 2006.

[32] J. J. Preibisz, J. E. Sealey, J. H. Laragh, R. J. Cody, and B. B. Weksler, "Plasma and platelet vasopressin in essential hypertension and congestive heart failure," Hypertension, vol. 5, no. 2, part 2, pp. I129-I138, 1983.

[33] M. Katan and M. Christ-Crain, "The stress hormone copeptin: a new prognostic biomarker in acute illness," Swiss Medical Weekly, vol. 140, article w13101, 2010.

[34] B. Müller, N. Morgenthaler, D. Stolz et al., "Circulating levels of copeptin, a novel biomarker, in lower respiratory tract infections," European Journal of Clinical Investigation, vol. 37, no. 2, pp. 145-152, 2007.

[35] N. G. Morgenthaler, B. Müller, J. Struck, A. Bergmann, H. Redl, and M. Christ-Crain, "Copeptin, a stable peptide of the arginine vasopressin precursor, is elevated in hemorrhagic and septic shock," Shock, vol. 28, no. 2, pp. 219-226, 2007.

[36] M. Katan, F. Fluri, N. G. Morgenthaler et al., "Copeptin: a novel, independent prognostic marker in patients with ischemic stroke," Annals of Neurology, vol. 66, no. 6, pp. 799-808, 2009.

[37] G. Sang, J.-M. Du, Y.-Y. Chen, Y.-B. Chen, J.-X. Chen, and Y.-C. Chen, "Plasma copeptin levels are associated with prognosis of severe acute pancreatitis," Peptides, vol. 51, pp. 4-8, 2014.

[38] S. Q. Khan, O. S. Dhillon, R. J. O’Brien et al., "C-terminal provasopressin (copeptin) as a novel and prognostic marker in acute myocardial infarction: leicester acute myocardial infarction peptide (LAMP) study," Circulation, vol. 115, no. 16, pp. 2103-2110, 2007.

[39] M. Katan, N. Morgenthaler, I. Widmer et al., "Copeptin, a stable peptide derived from the vasopressin precursor, correlates with the individual stress level," Neuroendocrinology Letters, vol. 29, no. 3, pp. 341-346, 2008.

[40] Y. L. Gu, A. A. Voors, F. Zijlstra et al., "Comparison of the temporal release pattern of copeptin with conventional biomarkers in acute myocardial infarction," Clinical Research in Cardiology, vol. 100, no. 12, pp. 1069-1076, 2011.

[41] G. Szinnai, N. G. Morgenthaler, K. Berneis et al., "Changes in plasma copeptin, the C-terminal portion of arginine vasopressin during water deprivation and excess in healthy subjects,"
The Journal of Clinical Endocrinology \& Metabolism, vol. 92, no. 10, pp. 3973-3978, 2007.

[42] H. Hupf, D. Grimm, G. A. J. Riegger, and H. Schunkert, "Evidence for a vasopressin system in the rat heart," Circulation Research, vol. 84, no. 3, pp. 365-370, 1999.

[43] C. Liebetrau, H. Nef, S. Szardien et al., "Release kinetics of copeptin in patients undergoing transcoronary ablation of septal hypertrophy," Clinical Chemistry, vol. 59, no. 3, pp. 566-569, 2013.

[44] S. J. Reinstadler, G. Klug, H.-J. Feistritzer et al., "Long-term predictive value of copeptin after acute myocardial infarction: a cardiac magnetic resonance study," International Journal of Cardiology, vol. 172, no. 2, pp. e359-e360, 2014.

[45] S. J. Reinstadler, G. Klug, H.-J. Feistritzer et al., "Association of copeptin with myocardial infarct size and myocardial function after ST segment elevation myocardial infarction," Heart, vol. 99, no. 20, pp. 1525-1529, 2013.

[46] F. Stallone, R. Twerenbold, K. Wildi et al., "Prevalence, characteristics and outcome of non-cardiac chest pain and elevated copeptin levels," Heart, vol. 100, no. 21, pp. 1708-1714, 2014.

[47] T. Reichlin, W. Hochholzer, C. Stelzig et al., "Incremental value of copeptin for rapid rule out of acute myocardial infarction," Journal of the American College of Cardiology, vol. 54, no. 1, pp. 60-68, 2009.

[48] T. Keller, S. Tzikas, T. Zeller et al., "Copeptin improves early diagnosis of acute myocardial infarction," Journal of the American College of Cardiology, vol. 55, no. 19, pp. 2096-2106, 2010.

[49] M. J. Lipinski, R. O. Escárcega, F. D’Ascenzo et al., "A systematic review and collaborative meta-analysis to determine the incremental value of copeptin for rapid rule-out of acute myocardial infarction," The American Journal of Cardiology, vol. 113, no. 9, pp. 1581-1591, 2014.

[50] T. Raskovalova, R. Twerenbold, P. O. Collinson et al., "Diagnostic accuracy of combined cardiac troponin and copeptin assessment for early rule-out of myocardial infarction: a systematic review and meta-analysis," European Heart Journal: Acute Cardiovascular Care, vol. 3, no. 1, pp. 18-27, 2014.

[51] S. von Haehling, J. Papassotiriou, N. G. Morgenthaler et al., "Copeptin as a prognostic factor for major adverse cardiovascular events in patients with coronary artery disease," International Journal of Cardiology, vol. 162, no. 1, pp. 27-32, 2012.

[52] A. Gegenhuber, J. Struck, B. Dieplinger et al., "Comparative evaluation of B-type natriuretic peptide, mid-regional proA-type natriuretic peptide, mid-regional pro-adrenomedullin, and Copeptin to predict 1-year mortality in patients with acute destabilized heart failure," Journal of Cardiac Failure, vol. 13, no. 1, pp. 42-49, 2007.

[53] S. Neuhold, M. Huelsmann, G. Strunk et al., "Comparison of copeptin, B-type natriuretic peptide, and amino-terminal proB-type natriuretic peptide in patients with chronic heart failure: prediction of death at different stages of the disease," Journal of the American College of Cardiology, vol. 52, no. 4, pp. 266-272, 2008.

[54] H. Bosselmann, M. Egstrup, K. Rossing et al., "Prognostic significance of cardiovascular biomarkers and renal dysfunction in outpatients with systolic heart failure: a long term follow-up study," International Journal of Cardiology, vol. 170, no. 2, pp. 202-207, 2013.

[55] L. Balling, C. Kistorp, M. Schou et al., "Plasma copeptin levels and prediction of outcome in heart failure outpatients: relation to hyponatremia and loop diuretic doses," Journal of Cardiac Failure, vol. 18, no. 5, pp. 351-358, 2012. 
[56] A. Maisel, Y. Xue, K. Shah et al., "Increased 90-day mortality in patients with acute heart failure with elevated copeptin: secondary results from the Biomarkers in Acute Heart Failure (BACH) study," Circulation: Heart Failure, vol. 4, no. 5, pp. 613620, 2011.

[57] D. Bar-Shalom, M. K. Poulsen, L. M. Rasmussen et al., "Plasma copeptin as marker of cardiovascular disease in asymptomatic type 2 diabetes patients," Diabetes and Vascular Disease Research, vol. 11, no. 6, pp. 448-450, 2014.

[58] G. Velho, N. Bouby, S. Hadjadj et al., "Plasma copeptin and renal outcomes in patients with type 2 diabetes and albuminuria," Diabetes Care, vol. 36, no. 11, pp. 3639-3645, 2013.

[59] I. J. Riphagen, W. E. Boertien, A. Alkhalaf et al., "Copeptin, a surrogate marker for arginine vasopressin, is associated with cardiovascular and all-cause mortality in patients with type 2 diabetes (ZODIAC-31)," Diabetes Care, vol. 36, no. 10, pp. 32013207, 2013.

[60] R. Seligman, J. Papassotiriou, N. G. Morgenthaler, M. Meisner, and P. J. Z. Teixeira, "Copeptin, a novel prognostic biomarker in ventilator-associated pneumonia," Critical Care, vol. 12, no. 1, article R11, 2008.

[61] M. Kolditz, M. Halank, B. Schulte-Hubbert, S. Bergmann, S. Albrecht, and G. Höffken, "Copeptin predicts clinical deterioration and persistent instability in community-acquired pneumonia," Respiratory Medicine, vol. 106, no. 9, pp. 1320-1328, 2012.

[62] D. Stolz, M. Christ-Crain, N. G. Morgenthaler et al., "Copeptin, C-reactive protein, and procalcitonin as prognostic biomarkers in acute exacerbation of COPD," Chest, vol. 131, no. 4, pp. 10581067, 2007.

[63] Q. Zhang, G. Dong, X. Zhao, M. Wang, and C. S. Li, "Prognostic significance of hypothalamic-pituitary-adrenal axis hormones in early sepsis: a study performed in the emergency department," Intensive Care Medicine, vol. 40, no. 10, pp. 1499-1508, 2014.

[64] P. Ostadal, A. Kruger, V. Zdrahalova et al., "Blood levels of copeptin on admission predict outcomes in out-of-hospital cardiac arrest survivors treated with therapeutic hypothermia," Critical Care, vol. 16, no. 5, article R187, 2012.

[65] N. P. Nickel, R. Lichtinghagen, H. Golpon et al., "Circulating levels of copeptin predict outcome in patients with pulmonary arterial hypertension," Respiratory Research, vol. 14, no. 1, article 130, 2013.

[66] G. M. De Marchis, A. Weck, H. Audebert et al., "Copeptin for the prediction of recurrent cerebrovascular events after transient ischemic attack: results from the CoRisk study," Stroke, vol. 45, no. 10, pp. 2918-2923, 2014.

[67] W.-J. Tu, X. Dong, S.-J. Zhao, D.-G. Yang, and H. Chen, "Prognostic value of plasma neuroendocrine biomarkers in patients with acute ischaemic stroke," Journal of Neuroendocrinology, vol. 25, no. 9, pp. 771-778, 2013.

[68] J.-L. Zhang, C.-H. Yin, Y. Zhang, L.-B. Zhao, H.-J. Fu, and J.C. Feng, "Plasma copeptin and long-term outcomes in acute ischemic stroke," Acta Neurologica Scandinavica, vol. 128, no. 6, pp. 372-380, 2013.

[69] D. B. Yang, W. H. Yu, X. Q. Dong et al., "Plasma copeptin level predicts acute traumatic coagulopathy and progressive hemorrhagic injury after traumatic brain injury," Peptides, vol. 58, pp. 26-29, 2014.

[70] G.-F. Yu, Q. Huang, W.-M. Dai et al., "Prognostic value of copeptin: one-year outcome in patients with traumatic brain injury," Peptides, vol. 33, no. 1, pp. 164-169, 2012.
[71] X. Q. Dong, M. Huang, S. B. Yang, W. H. Yu, and Z. Y. Zhang, "Copeptin is associated with mortality in patients with traumatic brain injury," Journal of Trauma-Injury, Infection and Critical Care, vol. 71, no. 5, pp. 1194-1198, 2011.

[72] W.-H. Yu, W.-H. Wang, X.-Q. Dong et al., "Prognostic significance of plasma copeptin detection compared with multiple biomarkers in intracerebral hemorrhage," Clinica Chimica Acta, vol. 433, pp. 174-178, 2014.

[73] Z. J. Wei, Y. Q. Ou, X. Li, and H. Li, “The 90-day prognostic value of copeptin in acute intracerebral hemorrhage," Neurological Sciences, vol. 35, no. 11, pp. 1673-1679, 2014.

[74] V. Maravic-Stojkovic, L. J. Lausevic-Vuk, M. Obradovic et al., "Copeptin level after carotid endarterectomy and perioperative stroke," Angiology, vol. 65, no. 2, pp. 122-129, 2014.

[75] S. Dong, C. L. Li, W. D. Liang, M. H. Chen, Y. T. Bi, and X. W. $\mathrm{Li}$, "Postoperative plasma copeptin levels independently predict delirium and cognitive dysfunction after coronary artery bypass graft surgery," Peptides, vol. 59, pp. 70-74, 2014.

[76] X. Li, X.-C. Yang, Q.-M. Sun, X.-D. Chen, and Y.-C. Li, "Brain natriuretic peptide and copeptin levels are associated with cardiovascular disease in patients with chronic kidney disease," Chinese Medical Journal, vol. 126, no. 5, pp. 823-827, 2013.

[77] W. E. Boertien, E. Meijer, D. Zittema et al., "Copeptin, a surrogate marker for vasopressin, is associated with kidney function decline in subjects with autosomal dominant polycystic kidney disease," Nephrology Dialysis Transplantation, vol. 27, no. 11, pp. 4131-4137, 2012.

[78] D. Zittema, W. E. Boertien, A. P. van Beek et al., "Vasopressin, copeptin, and renal concentrating capacity in patients with autosomal dominant polycystic kidney disease without renal impairment," Clinical Journal of the American Society of Nephrology, vol. 7, no. 6, pp. 906-913, 2012.

[79] L. Pang, H. L. Wang, Z. H. Wang et al., "Plasma copeptin as a predictor of intoxication severity and delayed neurological sequelae in acute carbon monoxide poisoning," Peptides, vol. 59, pp. 89-93, 2014.

[80] B. Karbek, M. Ozbek, M. Karakose et al., "Copeptin, a surrogate marker for arginine vasopressin, is associated with cardiovascular risk in patients with polycystic ovary syndrome," Journal of Ovarian Research, vol. 7, no. 1, article 31, 2014.

[81] A. Tuten, M. Kucur, M. Imamoglu et al., "Copeptin is associated with the severity of endometriosis," Archives of Gynecology and Obstetrics, vol. 290, no. 1, pp. 75-82, 2014.

[82] E. H. Yeung, A. Liu, J. L. Mills et al., "Increased levels of copeptin before clinical diagnosis of preelcampsia," Hypertension, vol. 64, no. 6, pp. 1362-1367, 2014.

[83] E. Zulfikaroglu, M. Islimye, E. A. Tonguc et al., "Circulating levels of copeptin, a novel biomarker in pre-eclampsia," The Journal of Obstetrics and Gynaecology Research, vol. 37, no. 9, pp. 1198-1202, 2011.

[84] F. K. Isman, B. Zulfikaroglu, B. Isbilen et al., "Copeptin is a predictive biomarker of severity in acute pancreatitis," American Journal of Emergency Medicine, vol. 31, no. 4, pp. 690-692, 2013.

[85] J.-P. Moreno, E. Grandclement, E. Monnet et al., "Plasma copeptin, a possible prognostic marker in cirrhosis," Liver International, vol. 33, no. 6, pp. 843-851, 2013.

[86] K. S. Akinlade, A. D. Atere, S. K. Rahamon, and J. A. Olaniyi, "Serum levels of copeptin, C-reactive protein and cortisol in different severity groups of sickle cell anaemia," Nigerian Journal of Physiological Sciences, vol. 28, no. 2, pp. 159-164, 2013. 
[87] C. Meune, S. Zuily, K. Wahbi, Y.-E. Claessens, S. Weber, and C. Chenevier-Gobeaux, "Combination of copeptin and highsensitivity cardiac troponin $\mathrm{T}$ assay in unstable angina and non-ST-segment elevation myocardial infarction: a pilot study," Archives of Cardiovascular Diseases, vol. 104, no. 1, pp. 4-10, 2011.

[88] E. Giannitsis, T. Kehayova, M. Vafaie, and H. A. Katus, "Combined testing of high-sensitivity troponin $\mathrm{T}$ and copeptin on presentation at prespecified cutoffs improves rapid rule-out of non-ST-segment elevation myocardial infarction," Clinical Chemistry, vol. 57, no. 10, pp. 1452-1455, 2011.

[89] P. Ray, S. Charpentier, C. Chenevier-Gobeaux et al., "Combined copeptin and troponin to rule out myocardial infarction in patients with chest pain and a history of coronary artery disease," The American Journal of Emergency Medicine, vol. 30, no. 3, pp. 440-448, 2012.

[90] A. Maisel, C. Mueller, S.-X. Neath et al., "Copeptin helps in the early detection of patients with acute myocardial infarction: primary results of the CHOPIN trial (Copeptin Helps in the early detection of Patients with acute myocardial INfarction)," Journal of the American College of Cardiology, vol. 62, no. 2, pp. 150-160, 2013.

[91] M. Sebbane, S. Lefebvre, N. Kuster et al., "Early rule out of acute myocardial infarction in ED patients: Value of combined highsensitivity cardiac troponin T and ultrasensitive copeptin assays at admission," The American Journal of Emergency Medicine, vol. 31, no. 9, pp. 1302-1308, 2013.

[92] C. Chenevier-Gobeaux, Y. Freund, Y.-E. Claessens et al., "Copeptin for rapid rule out of acute myocardial infarction in emergency department," International Journal of Cardiology, vol. 166, no. 1, pp. 198-204, 2013.

[93] J. Thelin, C. Borna, D. Erlinge, and B. Öhlin, "The combination of high sensitivity troponin T and copeptin facilitates early ruleout of ACS: a prospective observational study," BMC Cardiovascular Disorders, vol. 13, article 42, 2013.

[94] C. Balmelli, C. Meune, R. Twerenbold et al., "Comparison of the performances of cardiac troponins, including sensitive assays, and copeptin in the diagnostic of acute myocardial infarction and long-term prognosis between women and men," American Heart Journal, vol. 166, no. 1, pp. 30-37, 2013.

[95] P. Collinson, D. Gaze, and S. Goodacre, "Comparison of contemporary troponin assays with the novel biomarkers, heart fatty acid binding protein and copeptin, for the early confirmation or exclusion of myocardial infarction in patients presenting to the emergency department with chest pain," Heart, vol. 100, no. 2, pp. 140-145, 2014.

[96] J. Duchenne, S. Mestres, and N. Dublanchet, "Diagnostic accuracy of copeptin sensitivity and specificity in patients with suspected non-ST-elevation myocardial infarction with troponin I below the 99th centile at presentation," BMJ Open, vol. 4, no. 3, Article ID e004449corrl, 2014.

[97] P. Llorens, M. Sánchez, P. Herrero, F. J. Martín-Sánchez, P. Piñera, and Ò. Miró, "The utility of copeptin in the emergency department for non-ST-elevation myocardial infarction rapid rule out: COPED-MIRRO study," European Journal of Emergency Medicine, vol. 21, no. 3, pp. 220-229, 2014.

[98] M. Karakas, J. L. Januzzi Jr., J. Meyer et al., "Copeptin does not add diagnostic information to high-sensitivity troponin $\mathrm{t}$ in low- to intermediate-risk patients with acute chest pain: results from the rule out myocardial infarction by computed tomography (ROMICAT) Study," Clinical Chemistry, vol. 57, no. 8, pp. 1137-1145, 2011.
[99] S. Charpentier, B. Lepage, F. Maupas-Schwalm et al., "Copeptin improves the diagnostic performance of sensitive troponin Iultra but cannot rapidly rule out non-ST-elevation myocardial infarction at presentation to an emergency department," Annals of Emergency Medicine, vol. 61, no. 5, pp. 549.e1-558.e1, 2013.

[100] M. Weber, O. Bazzino, J. L. N. Estrada et al., "Improved diagnostic and prognostic performance of a new high-sensitive troponin $\mathrm{T}$ assay in patients with acute coronary syndrome," The American Heart Journal, vol. 162, no. 1, pp. 81-88, 2011.

[101] T. Keller, T. Zeller, F. Ojeda et al., "Serial changes in highly sensitive troponin I assay and early diagnosis of myocardial infarction," Journal of the American Medical Association, vol. 306, no. 24, pp. 2684-2693, 2011.

[102] R. Body, S. Carley, G. McDowell et al., "Rapid exclusion of acute myocardial infarction in patients with undetectable troponin using a high-sensitivity assay," Journal of the American College of Cardiology, vol. 58, no. 13, pp. 1332-1339, 2011.

[103] N. Bandstein, R. Ljung, M. Johansson, and M. J. Holzmann, "Undetectable high-sensitivity cardiac troponin T level in the emergency department and risk of myocardial infarction," Journal of the American College of Cardiology, vol. 63, no. 23, pp. 2569-2578, 2014.

[104] M. Mockel, J. Searle, C. Hamm et al., "Early discharge using single cardiac troponin and copeptin testing in patients with suspected acute coronary syndrome (ACS): a randomized, controlled clinical process study," European Heart Journal, 2014.

[105] P. Collinson, S. Goodacre, D. Gaze, and A. Gray, "Very early diagnosis of chest pain by point-of-care testing: comparison of the diagnostic efficiency of a panel of cardiac biomarkers compared with troponin measurement alone in the RATPAC trial," Heart, vol. 98, no. 4, pp. 312-318, 2012.

[106] M. Than, L. Cullen, C. M. Reid et al., "A 2-h diagnostic protocol to assess patients with chest pain symptoms in the Asia-Pacific region (ASPECT): a prospective observational validation study," The Lancet, vol. 377, no. 9771, pp. 1077-1084, 2011.

[107] D. Kelly, I. B. Squire, S. Q. Khan et al., "C-terminal provasopressin (copeptin) is associated with left ventricular dysfunction, remodeling, and clinical heart failure in survivors of myocardial infarction," Journal of Cardiac Failure, vol. 14, no. 9, pp. 739-745, 2008.

[108] M. Möckel and J. Searle, "The positive predictive value of ctproAVP (copeptin) in patients with STEMI," Heart, vol. 99, no. 20, p. 1475, 2013.

[109] H. Narayan, O. S. Dhillon, P. A. Quinn et al., "C-terminal provasopressin (copeptin) as a prognostic marker after acute nonST elevation myocardial infarction: leicester acute myocardial infarction peptide II (LAMP II) study," Clinical Science, vol. 121, no. 2, pp. 79-89, 2011.

[110] D. Afzali, M. Erren, H. J. Pavenstädt et al., "Impact of copeptin on diagnosis, risk stratification, and intermediate-term prognosis of acute coronary syndromes," Clinical Research in Cardiology, vol. 102, no. 10, pp. 755-763, 2013.

[111] M. Sanchez, P. Llorens, P. Herrero, F. J. Martin-Sanchez, P. Pinera, and O. Miro, "The utility of copeptin in the emergency department as a predictor of adverse outcomes in non-ST-elevation acute coronary syndrome: the COPED-PAO study," Emergency Medicine Journal, vol. 31, no. 4, pp. 286-291, 2014.

[112] M. Potocki, T. Reichlin, S. Thalmann et al., "Diagnostic and prognostic impact of copeptin and high-sensitivity cardiac troponin $\mathrm{T}$ in patients with pre-existing coronary artery disease and suspected acute myocardial infarction," Heart, vol. 98, no. 7, pp. 558-565, 2012. 


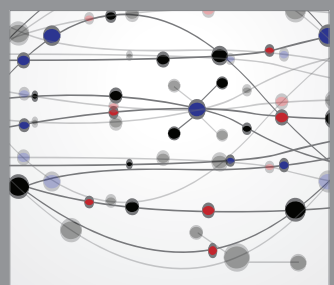

The Scientific World Journal
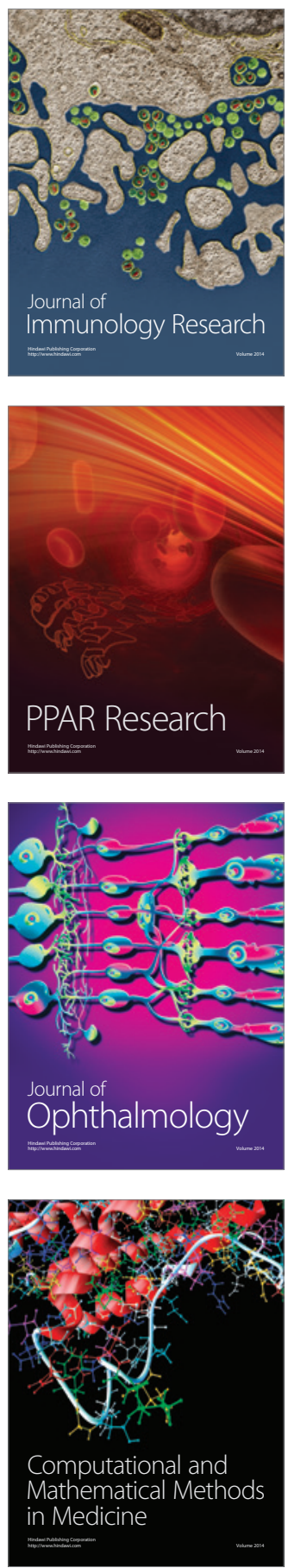

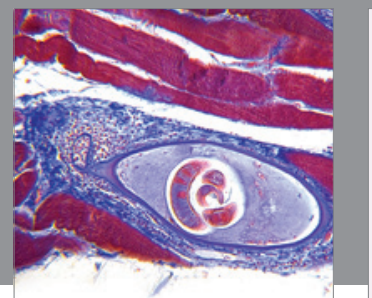

Gastroenterology

Research and Practice
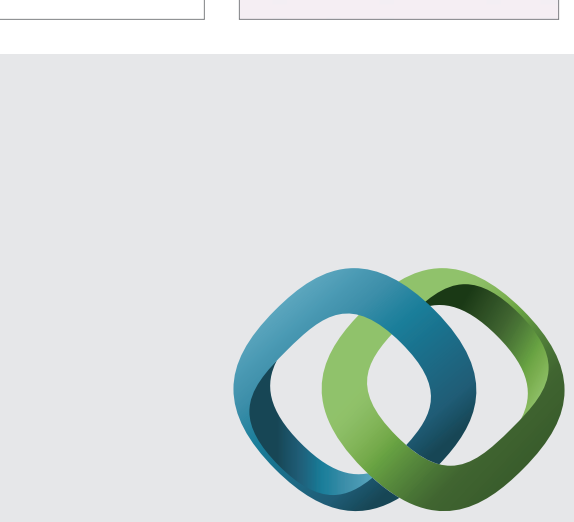

\section{Hindawi}

Submit your manuscripts at

http://www.hindawi.com
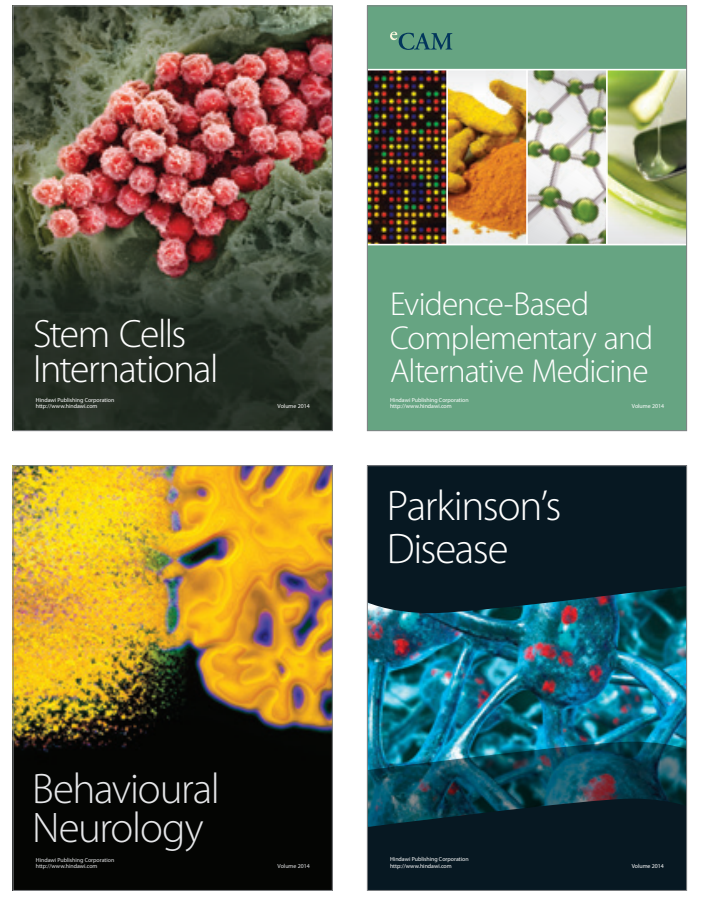
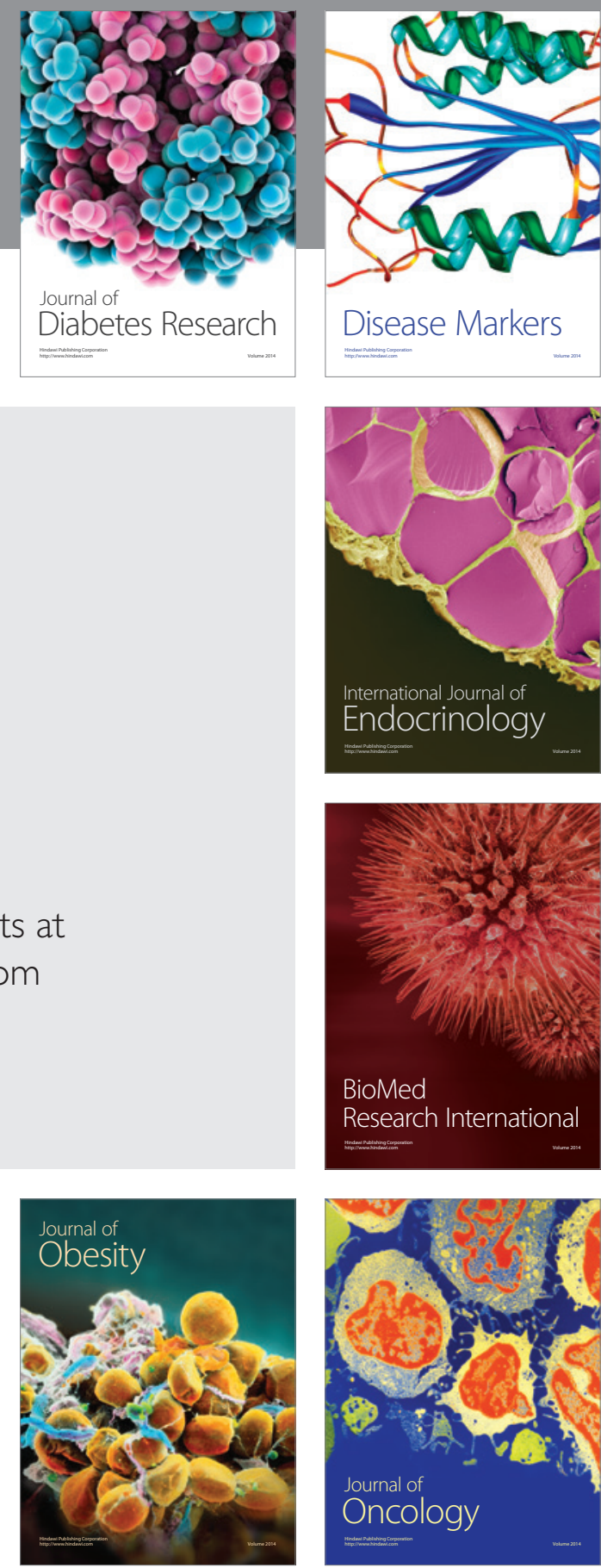

Disease Markers
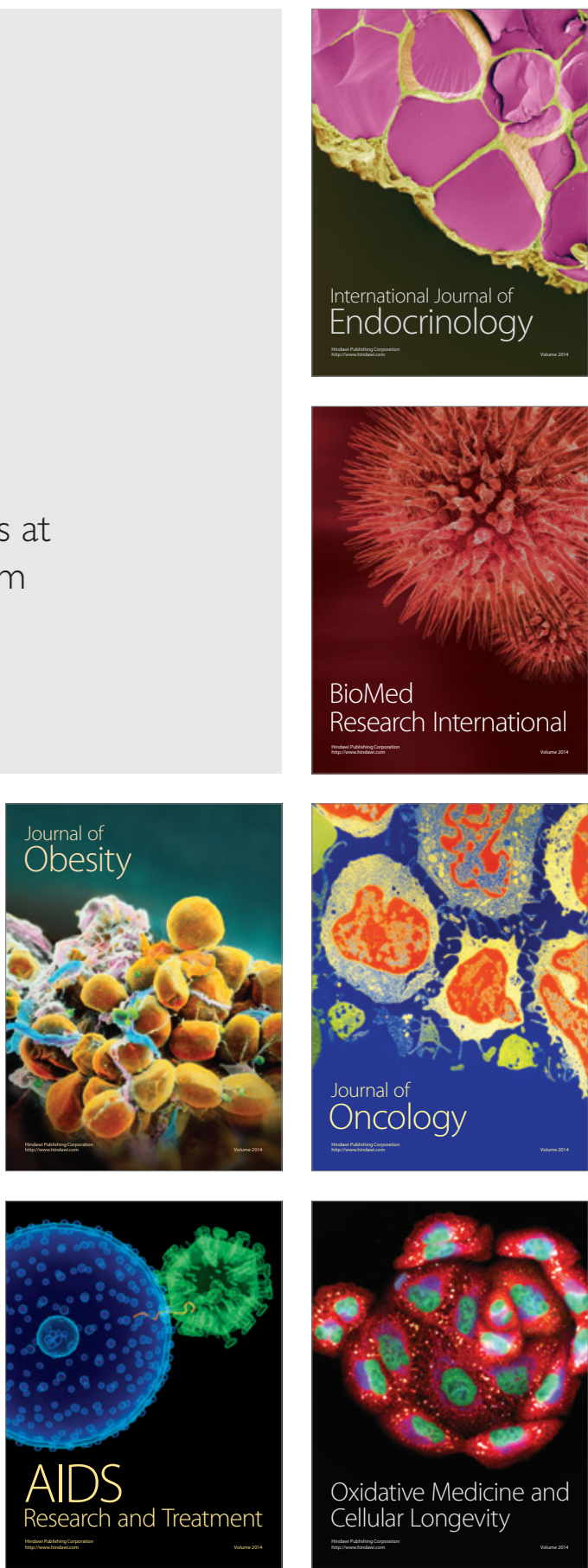